\title{
Estrutura Organizacional e Funcionamento das Universidades Brasileiras: revisão de literatura
}

\author{
Mario Rosa dos Santos ${ }^{1}$; Manoel Rodrigues Chaves ${ }^{2}$ \\ André Vasconcelos da Silva ${ }^{3}$; Fausto Teodoro Neves ${ }^{4}$
}

\section{Resumo}

Estrutura organizacional é uma organização, um grupo de pessoas que trabalham juntas para atingir metas comuns. Uma organização ao definir seus objetivos dá razões à sua existência, pois, a alta administração determina a direção da organização ao definir seus objetivos, estabelecer metas para atingi-los e formular estratégias para alcançar suas metas. As metas são os alvos da administração para atingir seus objetivos. As estratégias são planos de ações específicas que permitem a organização atingir as metas, e por consequência os objetivos. Esses são os elementos essenciais da estrutura organizacional.

A coordenação das estruturas organizacionais discute as vantagens e desvantagens da amplitude de controle, centralização e formalização, e relaciona esses elementos às estruturas organizacionais orgânicas e mecanicistas; identifica e avalia os tipos de departamentalização, explica como funciona o ambiente externo, o tamanho da organização, a tecnologia e a estratégia.

O presente estudo aborda a estrutura organizacional e participação no processo de gestão em universidades brasileiras, que visam introdução de novos arranjos organizacionais e de novos mecanismos de gestão para obtenção de mais eficiência no gasto público e sistemas educacionais eficientes e efetivos, com controle de resultados, da produtividade, dos custos, das metas, dos indicadores e do contrato de gestão, entre outros temas.

Palavras Chave: organização; inovação; desempenho.

1 Sociólogo, aluno do Programa de Mestrado Profissional em Gestão Organizacional da Universidade Federal de Goiás/Regional Catalão, Técnico-Administrativo da Universidade Federal de Goiás/Regional Goiânia. mrosa8@ gmail.com

2 Geógrafo, Docente do Programa de Mestrado Profissional em Gestão Organizacional da Universidade Federal de Goiás/Regional Catalão. manoelufg@ gmail.com

3 Professor Doutor no curso de Administração e do Programa de Mestrado Profissional em Gestão Organizacional da Universidade Federal de Goiás/Regional Catalão, Brasil.

andre.silva.ufg@gmail.com

4 Advogado, aluno especial do Programa de Mestrado Profissional em Gestão Organizacional da Universidade Federal de Goiás, Regional Catalão. Brasil. faustoteodoro.adv@ hotmail.com 


\section{Introdução}

A estrutura organizacional é um instrumento importante para guiar e fornecer recursos em relação à estratégia organizacional. Estrutura organizacional se refere à divisão do trabalho e também aos padrões de coordenação, comunicação, fluxo de trabalho e poder formal que norteiam a coordenação, além de ditar quais atividades recebem maior atenção e recursos financeiros, de poder e informação. A estrutura organizacional inclui relações hierárquicas, mas também tem a ver com a concepção das tarefas, o fluxo de informações, as normas e regras de trabalho, a dinâmica de equipe e as relações de poder. Assim, a estrutura organização é um instrumento importante para a mudança organizacional, pois estabelece novos padrões de comunicação e alinha o comportamento do funcionário com a visão da empresa (GRIFFIN E MOORHEAD, 2006).

Nos estudos sobre organização e estrutura organizacional, Griffin e Moorhead (2006), iniciam o texto definindo que uma organização estrutural é um grupo de pessoas que trabalham juntas para atingir metas comuns. Uma organização ao definir seus objetivos dá razões à sua existência, pois, a alta administração determina a direção da organização ao definir seus objetivos, estabelecer metas para atingi-los e formular estratégias para alcançar suas metas. As metas são os alvos da administração para atingir seus objetivos. E as estratégias são planos de ações específicas que permitem à organização atingir suas metas, e por consequência os objetivos. Esses são os elementos essenciais da estrutura organizacional.

Estrutura organizacional, segundo Costa, Souza e Fell (2012), é algo imprescindível, independentemente do tamanho, de modo que toda corporação precisa de uma composição que funcione como ferramenta de controle por meio da distribuição de cargos, das relações interpessoais, do planejamento dos objetivos e metas, a fim de facilitar o ajuste organizacional e levar as pessoas a se responsabilizarem por um funcionamento o mais adequado e eficiente possível da organização.

A presente revisão de literatura tem como objetivo especificar os estudos aprofundados sobre estrutura organizacional, apresentados por Griffin e Moorhead (2006). Conforme autores citados, um organograma retrata a estrutura organizacional, mostram todas as pessoas, cargos, relações de subordinação e linhas de comunicação formal de uma organização. Nesse organograma se formam também a configuração, processos ou formas de organização que podem ser analisadas conforme a consecução de dois requisitos estruturais básicos: divisão do trabalho e coordenação da divisão de tarefas. Em seguida se formam uma investigação detalhada dos quatro elementos principais da estrutura organizacional: amplitude de controle, centralização, formalização e departamentalização. E por fim, destacam as contingências do projeto organizacional, incluindo o ambiente externo, o tamanho da organização, a tecnologia e a estratégia.

\section{Processos na Estrutura Organizacional}

\subsection{Divisão do trabalho}

A divisão do trabalho se refere à subdivisão do trabalho em tarefas distintas atribuídas a pessoas diferentes. Para Griffin e Moorhead (2006), o trabalho subdividido leva à especialização do trabalho porque cada função inclui um conjunto 
restrito de tarefas necessárias para concluir o produto ou serviço. À medida que as empresas ficam maiores, há uma divisão horizontal do trabalho e por consequência leva a uma divisão vertical: algumas pessoas são designadas para a tarefa de supervisionar, outras são responsáveis por gerir os supervisores e assim por diante.

O sistema de comunicação, importante componente da estrutura organizacional, de acordo com Kunsch (2014), deve operar de forma a permitir que o fluxo de informações atinja todos os envolvidos dentro da instituição de maneira efetiva, pois são as pessoas que, ao comunicarem entre si, viabilizam o sistema (interação entre as partes), de forma que se garanta a sobrevivência e a consecução dos objetivos organizacionais no novo ambiente vivo de interação.

Kunsch (2014) entende que implantação e exercício da comunicação organizacional devem ser adotados e praticados enquanto administração estratégica, a qual, segundo Beltrame e Alperstedt (2015), se dá ao atingir toda organização e não apenas a uma pessoa ou grupo (por ser uma responsabilidade de todos), não desconsiderando fatores como: o novo ambiente; públicos de interesses; estabelecimento de uma cultura comunicacional, com canais de relacionamento; saberes, competências e experiências das pessoas.

\subsection{Coordenação}

Ao dividir o trabalho, há a necessidade de mecanismos de coordenação para garantir a execução articulado da produção. Para Griffin e Moorhead (2006), a coordenação está tão intimamente ligada à divisão do trabalho que o nível ideal de especialização é limitado pela viabilidade de coordenar o trabalho. Por outro lado, a coordenação também tende a se tornar mais cara e difícil à medida que a divisão do trabalho aumenta.

\section{Elementos da Estrutura Organizacional}

\subsection{Amplitude de controle}

A quantidade de pessoas que se reporta diretamente ao próximo nível de hierarquia é definida como sendo amplitude de controle. Para Griffin e Moorhead (2006), as operações de produção com melhor desempenho atualmente se baseiam em equipes autodirigidas, de modo que a supervisão direta (hierarquia formal) é suplantada por outros mecanismos de coordenação, como por meio da comunicação informal e do conhecimento especializado. Outro fator que influencia a melhor amplitude de controle é se os funcionários executam tarefas rotineiras ou o grau de interdependência dos funcionários em um departamento. Portanto, a amplitude de controle está ligada ao tamanho da organização (número de funcionários) e ao número de camadas na hierarquia dessa organização.

\subsection{Centralização e Descentralização}

A centralização e a descentralização são elementos importantes quando se projeta uma estrutura organizacional. Segundo Griffin e Moorhead (2006), a centralização significa que a autoridade formal para a tomada de decisão é detida por um pequeno grupo de pessoas, geralmente as que estão no topo da hierarquia organizacional. À medida que as organizações crescem, seus ambientes se tornam 
mais complexos e a tendência é da organização descentralizar, isto é, dispersar a autoridade decisória e o poder por toda a organização.

\subsection{Formalização}

A formalização é o grau em que as organizações padronizam o comportamento por meio de regras, treinamento formal e mecanismos correlatos, ou seja, as empresas se tornam mais formais à medida que aumentam as formas de padronização para coordenar o trabalho. As empresas mais antigas e maiores tendem a se tornarem mais formalizadas, seja porque as atividades de trabalho se tornam mais rotineiras, ou seja, porque a supervisão direta e a comunicação informal entre os funcionários não funcionam com grande quantidade de pessoas. A formalização pode até aumentar a eficiência e a obediência, porém pode criar problemas como a aprendizagem e a criatividade organizacional. Griffin e Moorhead (2006) reforçam que o desafio enfrentado pelas empresas quando ficam maiores e mais velhas é evitar o excesso de formalização.

\subsection{Departamentalização}

A departamentalização é o elemento que especifica como os funcionários e suas atividades são agrupadas. Consiste na forma de associar as tarefas divididas e distribuí-las a cada grupo de trabalho. A departamentalização estabelece a cadeia de comando, concentra as pessoas em torno de modelos mentais comuns e estimula determinadas pessoas a coordenarem por meio da comunicação informal.

Griffin e Moorhead (2006) citam os seis tipos puros de departamentalização mais comuns: simples, funcional, divisional, baseado em equipes, matricial e em rede. A maioria das empresas começa com uma estrutura simples, oferecem apenas um produto ou serviço distinto, hierarquia mínima e altamente flexível. $\mathrm{Na}$ estrutura funcional, os funcionários são organizados em torno de conhecimentos específicos ou de outros recursos, supervisão direta e maior dificuldade agrupar conflitos e de coordenação no atendimento aos clientes ou no desenvolvimento de produtos. A estrutura divisional os funcionários são organizados em torno de áreas geográficas, resultados (produtos/serviços) e clientes. A estrutura baseada em equipes, a estrutura organizacional é criada em torno de equipes autodirigidas que realizam um trabalho completo. Esse tipo de estrutura geralmente é organiza. Há uma grande amplitude de controle, pois as equipes atuam com supervisão mínima. A estrutura baseada em equipes tem conquistado popularidade porque tende a ser flexível e a responder aos ambientes turbulentos. A estrutura matricial reveste duas estruturas a fim de aproveitar os benefícios de ambas. E por último, a estrutura em rede é a aliança de várias organizações com o propósito de criar um produto ou atender um cliente.

\section{Contingências do Projeto Organizacional}

Griffin e Moorhead (2006) afirmam que a maioria das teorias e conceitos de comportamento organizacional possui contingências, ou seja, idéias que funcionam bem em uma situação que podem não funcionar em outra. $\mathrm{Na}$ abordagem contingencial da estruturação organizacional os resultados desejados podem ser atingidos de várias formas. Para aumentar a eficiência da organização alguns elementos são essências, tais como os fatores contingências que incluem a 
estratégia da organização, a tecnologia disponível, o ambiente, o tamanho da organização e a sociedade em que ela atua.

A contingência ambiente externo abrange qualquer coisa fora da organização, o que inclui a maioria das partes interessadas, recursos e concorrentes. Na contingência tamanho, à medida que a empresa cresce, cresce também o número de funcionários por consequência cresce a especialização da função em virtude da divisão do trabalho a qual requer mecanismos de coordenação mais elaborado. Em razão disso as empresas utilizam mais a padronização (processos de trabalho e dos resultados) para coordenar as atividades de trabalho.

A contingência tecnologia se refere aos mecanismos ou processos pelos quais uma organização gera seus produtos ou serviços. E a contingência estratégia organizacional se refere à maneira que a organização se posiciona no seu contexto em relação às partes interessadas, dados os recursos, as capacitações e a missão da organização, ou seja, a estratégia representa as decisões e ações aplicadas para alcançar os objetivos organizacionais.

No entendimento de Costa, Souza e Fell (2012) e de Barbalho (2012), a organização atenta às condições externas percebe mais rapidamente as ameaças, como também, as oportunidades de crescimento organizacional, pois está aberta a mudanças, buscando melhor adequação aos processos organizacionais.

\section{Estrutura Organizacional das Universidades Brasileiras.}

No tópico "Estrutura organizacional e desempenho", Leitão (1990) afirma que a estrutura de uma organização e seu processo decisório é aceita pela maioria dos estudiosos de organização; e diferentes processos decisórios correspondem a diferentes estruturas organizacionais. Isso demonstra, segundo o autor, os efeitos da estrutura sobre as formas de decidir.

Outro ponto levantado por ele é saber se a estrutura segue a decisão estratégica, ou se é a decisão estratégica que é influenciada pela estrutura. Por outro lado, ele diz que a estrutura seria dominante nas organizações onde não tivesse sido institucionalizada uma estratégia global.

Leitão (1990) cita Pfeffer o qual aponta que as diferenças existentes nas estruturas dominantes de cada organização podem explicar seus diferentes processos decisórios. Assim, se uma instituição apresenta uma estrutura altamente centralizada, a unidade de análise do processo decisório será o indivíduo. Se a formalização é a dimensão dominante, a organização como um todo será a unidade enfocada. Se for tipicamente complexa, uma abordagem psicossocial dos pequenos grupos que a integram será o método de análise. Outro ponto a ser considerado na análise estrutural é a hierarquia de autoridade, porque segundo Leitão (1990), ela define as metas organizacionais e está intimamente relacionada à sequência meiofim na instituição.

$\mathrm{Na}$ universidade, segundo Leitão (1990), na tipologia de Etzioni, a hierarquia de autoridade do especialista, fundamentada em princípios fortemente individualizados, se opõe ao princípio da administração que supõe hierarquia de poder, com o controle e a coordenação exercida por superiores, conforme o princípio da autoridade burocrática. Por outro lado, a tecnoestrutura é necessária na medida em que a padronização que orienta o trabalho dos professores e pesquisadores é resultado de treinamento externo. Nesse tipo de estrutura requer um processo decisório descentralizado. 
Assim, segundo Leitão (1990), chegaremos a uma conclusão básica, a de que existe um desajuste estrutural na universidade pública brasileira, consequente da transposição de modelo de administração que o Governo utiliza nos demais órgãos públicos para a universidade, sem observar inteiramente as características específicas desse tipo de organização.

Nesse sentido, segundo Leitão (1990), a estrutura organizacional, incluindo as universidades, depende diretamente de decisões políticas onde predomina os interesses do Estado ou dos grupos hegemônicos nele representados. A influência dessas decisões é exercida principalmente pelo controle orçamentário fortemente centralizado nos órgãos executivos da União e pela formalização das decisões superiores, através de um considerável número de leis, decretos e portarias. $O$ processo decisório tem início na Presidência da República, Secretaria de Planejamento e Ministério de Educação e Cultura, deixando menos espaço para as decisões tomadas na administração das universidades e nos seus colegiados.

\subsection{Cultura Organizacional e Desempenho}

No tópico "Cultura organizacional e desempenho", Leitão (1990) diz que há um vínculo entre cultura e estrutura organizacional quando se pensa na descentralização como forma adequada às organizações de alto grau de complexidade como as universidades. Nesse tipo de organização, questões estratégicas são difíceis de buscar um consenso na instituição, tendo em vista as diferentes percepções de seus membros, os vieses profissionais e influências corporativas.

Para Leitão (1990), a barganha política tem sido a solução apontada para administrar essas diferentes visões da realidade e ela é, sem dúvida, indispensável a organizações com tais características. Nos sistemas descentralizados, a cultura pode exercer função agregadora, alcançando a concordância dos membros sem a necessidade de coerção e fiscalização contínua.

Segundo Leitão (1990), citando Weick "tanto a cultura como as operações padronizadas podem impor ordem e substituir a administração centralizada, mas é a cultura que mais fornece capacidade de interpretação, improvisação e ação coordenada". Weick chega a afirmar que antes de se descentralizar uma instituição, é preciso primeiro centralizar, para que se processe a socialização do pessoal, para que aprendam a compartilhar suposições e premissas de decisões, o que é feito pela cultura.

Para Leitão (1990), uma das deduções extraídas da posição de Weick é que a cultura não só perpassa a estrutura organizacional, como pode, por vezes, substituíla, minimizando sua importância, quando substitui a centralização ou reduz o papel da hierarquia.

Wilkins e Ouchi, segundo Leitão (1990), dedicaram-se às relações entre cultura e eficiência. Essa visão de Wilkins e Ouchi aplicada à universidade permite supor a possibilidade de formação de clãs profissionais entre seus especialistas com treinamentos profissionais comuns e reunidos para a realização de tarefas específicas. Devido à complexidade da universidade torna mais difícil a integração de seus vários grupos, podem ai ocorrer culturas alternativas, como os grupos corporativos.

Já Smircich, segundo Leitão (1990), a cultura tem um enfoque que é denominado de "metáfora da raiz" que trata a cultura como um plano epistemológico que permite estruturar o estudo das organizações como um fenômeno social e 
identifica três linhas de pesquisa: conhecimento organizacional, baseada na teoria do mesmo nome e na antropologia cognitiva; simbolismo organizacional, tendo como referência teórica o simbolismo das organizações e a antropologia simbólica; e do processo inconsciente e organização que tem como bases a teoria transformadora da organização e a antropologia de Lévi-Strauss.

Leitão (1990) afirma que os diferentes entendimentos sobre a natureza específica da cultura - cognitiva, simbólica, estruturalista ou psicodinâmica - têm em comum, segundo Smircich, o tratamento da organização como forma particular de expressão humana, como manifestação inconsciente, entendendo-a, analisando-a não em seus aspectos puramente econômicos, mas em termos idealistas e simbólicos.

A conclusão a que chega Leitão (1990) é que impressão que fica quando se procede a um exame das relações entre estrutura, cultura e desempenho organizacional é a de se estar pisando em terreno arenoso.

A primeira evidência para Leitão (1990) está na inter-relação existente entre fatores estruturais e culturais, como, por exemplo, na conexão entre os clãs e a complexidade da estrutura, ou entre centralização/descentralização e cultura, ou ainda entre estrutura de autoridade, autonomia e cultura vinculadas à forma como se exerce o poder na organização.

Há também indícios de que tanto o fator estrutural como o cultural tem, de forma integrada, contribuições para o desempenho institucional que precisam ser melhores conhecidas. Há, sem dúvida, problemas teóricos e metodológicos. A forma como a cultura explica o desempenho, nas abordagens anteriormente examinadas, parece ser uma questão de natureza eminentemente teórica. Mas existem também problemas metodológicos a serem resolvidos (LEITÃO, 1990).

Necessita-se, portanto, de uma metodologia que atenda a essa característica e que tenha o necessário rigor para se tomar confiável, o que não constitui problema simples. Será preciso definir ainda se uma avaliação qualitativa do desempenho deverá desenvolver-se no sentido de uma avaliação da qualidade técnica da organização ou no sentido político da avaliação qualitativa, que dá significado diferente ao conceito de eficácia. (LEITÃO, 1990).

No artigo intitulado "Estrutura organizacional e gestão do desempenho nas universidades federais brasileiras", de 2003, de autoria de Eurípedes Falcão Vieira e Marcelo Milano Falcão Vieira, os autores fazem uma reflexão sobre desempenho gerencial e não sobre o desempenho acadêmico, ou seja, trata-se aqui de desempenho das atividades-meio, atividades de gestão operacional e por vezes estratégicas visando a atividades-fim. Além disso, versa sobre a questão da qualidade no que diz respeito aos processos administrativos e gerenciais das organizações universitárias.

Segundo Vieira e Vieira (2003), existem grandes e rápidas transformações causadas pela evolução tecnológica que introduzem novos paradigmas em nossas vidas. Ainda, segundo Vieira e Vieira (2003) esses novos paradigmas podem até não se constituir num determinismo para as organizações, mas instituição de qualidade, e precisam estar conectadas para usar as ferramentas da inovação tecnológica. Muitas das inovações tecnológicas são desenvolvidas dentro das instituições universitárias, porém mantém estruturas anacrônicas caracterizadas pela baixa eficiência, alto grau de burocratização na movimentação dos fluxos de gestão e lentas no poder decisório, a exemplo das universidades federais. 


\subsection{Estruturação Organizacional das Instituições Federais de Ensino Superior (IFES)}

No tópico "Estruturação organizacional como forma e tempo para a inovação" as estruturas organizacionais das instituições federais de ensino superior (IFES) foram instituídas em uma época que pode ser considerada irracionalismo burocrático. As estruturas piramidais dos sistemas burocráticos estão esgotadas como modelos de organização. A reestruturação conduzida pela reforma de 1968 contribuiu para elevar o grau de burocratização nas estruturas das IFES com a introdução do sistema departamental e com ela o crescimento dos procedimentos normativos. As IFES passaram a contar com estruturas altamente complexas com faculdades, centros, departamentos, escolas, institutos, além das coordenações de cursos e outros órgãos periféricos (VIEIRA e VIEIRA, 2003).

Segundo Vieira e Vieira (2003), um novo poder, burocrático internamente e sindical externamente, quase sempre representativo de uma corrente políticopartidária se instala progressivamente e evolui num contexto de forte espírito corporativista. O fortalecimento do poder sindical docente e técnico-administrativo sai dos pleitos reivindicatórios salariais, extrapolando gradativamente para problemas institucionais. A autoridade e a representação do Reitor caem significativamente. As questões de gestão do ensino superior são colocadas em bloco e discutidas por organizações intermediárias, representando reitores, docentes ou técnico-administrativos junto ao Ministério da Educação. Os sindicatos ou Associações, designados por Vieira e Vieira (2003) de poder paralelo ganham força e a gestão dos reitores fica extremamente engessada.

Para Vieira e Vieira (2003), será necessária uma reestruturação organizacional das IFES, favorecendo a adoção de novos procedimentos administrativos, formação de novos arranjos de poder, marcados pela simplicidade e com suporte na instrumentalidade estratégica, para romper com as três grandes patologias organizacionais dos órgãos públicos: o excesso de normatização, a complexidade burocrática e o corporativismo. Essas patologias tendem a desaparecer diante dos recursos das tecnologias virtuais, da flexibilidade orgânica e da descentralização do poder. Para Vieira e Vieira (2003), outro fator importante a ser considerado para uma nova visão das IFES será a autonomia universitária, essa autonomia não muda o status de universidade federal pública e gratuita, o que muda é a estrutura organizacional, a forma de gestão e as responsabilidades dos dirigentes.

\subsection{Condicionamentos estruturais e burocráticos}

No tópico "Condicionamentos estruturais e burocráticos ao exercício do poder e à gestão do desempenho qualificado", Vieira e Vieira (2003) afirmam que as universidades federais sofrem duas ordens de condicionamento em relação à inovação e à qualificação no exercício do poder e no desempenho. A primeira de ordem interna que é a resistência à mudança; e a segunda refere-se à distorcida relação das IES com o MEC. Esta relação acaba se tornando conflituosa, por outro lado, os reitores representam um poder de confiança de ambos os lados, da comunidade universitária e do MEC.

Vieira e Vieira (2003) apontam que os condicionamentos estruturais e burocráticos ao exercício do poder e à gestão do desempenho qualitativo podem ser analisados em diferentes dimensões: pela complexidade organizacional, pela 
isonomia salarial, pela qualidade e desempenho, pelo sistema de avaliação institucional e pela energia do sistema.

\subsection{Relações das Universidades Federais com o Ministério da Educação}

Outro tópico considerado por Vieira e Vieira (2003) foi as "Relações das universidades federais com o Ministério da Educação", para eles as universidades federais são órgãos vinculados ao Ministério da Educação, sendo assim, ficam sujeitas as normas de política oficial de educação superior, além da dependência orçamentária tanto de pessoal como de custeio e capital, portanto sujeitas a um enorme aparato burocrático e normativo. As diretrizes orçamentárias são impostas de cima para baixo, e não tendo autonomia financeira as universidades federais encontram inúmeras dificuldades para atender às novas demandas exigidas dentro de sistemas que a cada dia se renova.

A consequência, por sua vez, será de relações permanentemente conflituosas com o Ministério da Educação. Vieira e Vieira (2003) destacam alguns pontos críticos nas relações do MEC com as IFES: procedimentos e normas isonômicas a realidades desiguais; ambiente de confronto entre as IFES e o MEC; e uma autonomia precária. A consequência dessas relações conflituosas se dá pelas distorções sistêmicas, pela intermediação sindical e de órgãos associativos, causando a dependência e baixa flexibilidade de gestão.

Vieira e Vieira (2003), na tentativa de minimizar os conflitos entre as IFES e o MEC destacam que as novas relações devem se situar mais nos programas de apoio, ampliando os já existentes, alargando progressivamente a faixa de autonomia e minimizando a ação normativa.

\subsection{Nova Estrutura Organizacional: Modelo pós-burocrático}

Por fim, no tópico a "Tentativa de construção de um modelo pós-burocrático: flexibilidade organizacional na estruturação das IFES”, Vieira e Vieira (2003) desenham a concepção de uma nova estrutura organizacional baseada num modelo simplificado, pós-burocrático, que se orienta pela flexibilidade, agilidade, qualidade e racionalidade de custos. São novas estratégias de ação, sustentadas por sistemas de gestão informatizados, e a consequente desnormatização dos serviços, otimizando seus fluxos no espaço e no tempo através das vias tecnológicas, favorecendo a racionalização e a produtividade dos fluxos de demanda no âmbito dos serviços. O sistema de rede, a interação sistêmica, com o estabelecimento de códigos de comunicação, não só permite eficiência dos serviços, como representa um agente de reorganização das relações de poder.

$\mathrm{Na}$ atividade-fim, com a eliminação dos departamentos e demais entraves impostas às IFES, daria lugar à criação de institutos com estruturas mais amplas, mais flexíveis, mais interdisciplinares, conceituando-se áreas de conhecimento. Esses institutos incorporariam os cursos de graduação, pós-graduação, núcleos de pesquisa, centros especializados, museus, bibliotecas, órgãos de ação comunitária, projetos e programas. Toda essa estrutura estaria dentro de um arcabouço informatizado para facilitar seus procedimentos e fluxos em redes flexíveis e ágeis de organização acadêmica e administrativa. A teia do poder deixará de ser altamente hierarquizada e vertical, tornando-se mais direta e amplamente colegiada (VIEIRA e VIEIRA, 2003). 
Nas considerações finais, Vieira e Vieira (2003) delimitam o campo de análise na estrutura organizacional e o desempenho das universidades federais. Questões importantes como o poder e a gestão autônoma merecerão novas análises, pois representam atualmente uma ordem institucionalizada, geradora de grandes e profundos impasses no desempenho das organizações públicas de modo geral e das universidades federais em particular.

A perspectiva analítica seguida neste artigo foi a de identificar uma causa maior da crise universitária brasileira, e que respondesse pelo desencadeamento de ações e organicidades consideradas altamente burocratizantes, normativas e corporativas. Nesse espectro de complexidade estrutural, organizacional e funcional a instituição universitária pública federal produz e alimenta uma inércia sistêmica que a torna, dramaticamente, recalcitrante à inovação, expandida nas atividadesmeio e prejudicada nas atividades-fim por um desempenho de baixa energia. $A$ qualidade do sistema fica comprometida. A revolução das tecnologias, incluindo as de gestão, na última década, especialmente, produziu a pós-modernidade, que para - caso das universidades federais seria mais uma caracterização de tempos burocráticos e pós-burocráticos, ou seja, o que ainda representa o modelo burocrático do passado e o novo modelo pós-burocrático (VIEIRA e VIEIRA, 2003).

O objetivo final das universidades pública é a formação de profissionais qualificados. Para isso, segundo Vieira e Vieira (2003) precisa de uma configuração organizacional que possa disponibilizar as metodologias permanentemente renovadas capazes de agregar ao corpo discente os valores da cultura e das técnicas profissionalizantes. Então, será necessário um sistema pós-burocrático, estruturado numa ordem organizacional simples, informatizada e racional (VIEIRA e VIEIRA, 2003).

Este artigo discute uma visão objetiva da realidade das IFES e a perspectiva futura de introdução da inovação estrutural e, principalmente, a implantação de novas formas de organização acadêmica. Essas perspectivas, se concretizadas, serão capazes de gerar novo impulso à eficiência e, consequentemente, estabelecer novo padrão de funcionalidade que se refletirá no desempenho de qualidade das instituições federais de ensino superior (VIEIRA e VIEIRA, 2003).

Segundo Vieira e Vieira (2004), o Plano Estratégico de Desenvolvimento estabeleceu metas evolutivas à Universidade, dimensionadas não só para o ambiente interno, mas interconectando essas ações e as demandas sociais. A relação entre a Universidade e o ambiente externo estabelece-se por uma cumplicidade entre as demandas sociais e as estratégias e metas da Universidade.

A organização acadêmica e a sociedade interagem mutuamente. A sociedade oferece os indicadores à definição do perfil profissional adequado à realidade regional. A Universidade cria o ambiente interno adequado à implementação das estratégias e metas para o ensino, a pesquisa e a extensão. A organização acadêmica e a sociedade interagem mutuamente. A sociedade molda o perfil profissional adequado à realidade regional. Nos ambientes de interação, segundo as estratégias e metas estabelecidas, moldam-se os três grandes marcos da crise que afeta as universidades federais: perda da hegemonia; perda de legitimidade e as perdas institucionais ocorrem no ordenamento interno, na estrutura e na organização.

O artigo intitulado "Estrutura organizacional e gestão sob a ótica da teoria da contingência”, de 2010, de autoria de Jair Antônio Fagundes, Marly Petri, Rosália Barbosa Lavarda, Marcos Rogério Rodrigues, Carlos Eduardo Facin Lavarda e Cristina Crespo Soller, cujo objetivo é identificar como se classifica a estrutura 
organizacional e a gestão de uma empresa de fabricação e montagem de equipamentos industriais, sob a ótica da teoria contingencial.

O texto "Análisis Conductual Aplicado em la Educación superior", de 2011, de autoria de Guillermo E. Yáber (2011) comenta sobre a análise comportamental que consiste no estudo conceitual, estudos experimentais, desenvolvimento de tecnologias que se aplicado ao comportamento poderá promover mudanças no comportamento humano em diferentes níveis: o indivíduo em grupos, equipes em unidades de uma organização e na organização como um todo e em sistemas sociais.

Yáber (2011) descreve e ilustra, ainda, a aplicação dessa abordagem para o estudo do comportamento na gestão do desempenho das Instituições Federais do Ensino Superior (IFES) nos processos e tarefas de grupo e individual, na gestão do currículo e na concepção de instrução no ensino superior. A análise comportamental pode tirar proveito do desenvolvimento das tecnologias da informação e comunicação para melhorar significativamente os projetos de instrução do ensino superior.

Yáber (2011) tem com objetivo apresentar esquematicamente as premissas conceituais da análise comportamental e análise de sistemas comportamentais e indicar, exemplificar e discutir sobre o escopo dos aplicativos de análise comportamental no ensino superior. A análise comportamental aplicada no Ensino Superior tem um enfoque da psicologia como ciência da conduta (Malott, Malott, y Trojan, 2003; Pierce y Cheney, 2008), sendo uma referência conceitual de métodos e aplicações que podem contribuir para a gestão de currículo, otimizar o ensino e melhorar o desempenho individual e em grupo de unidades das instituições do ensino superior.

A análise comportamental e análise de sistemas comportamentais buscam de forma sintética os fundamentos da análise do comportamento como uma abordagem para a psicologia comportamental e análise de sistemas como o uso combinado da análise do comportamento e a análise de sistemas para ajudar as organizações a alcançar seus objetivos. A análise comportamental e gestão de desempenho no Ensino Superior, educação pode ser compreendida como um macro sistema que inclui o subsistema de ensino superior e dentro deste subsistema, as universidades, como organização; ocupa um espaço fundamental através de seus processos de ensino, pesquisa e extensão cuja missão é gerar conhecimentos, formar talentos e prestação de serviços. A Instrução, análise comportamental e as tecnologias da informação e da comunicação constituem um desafio para a educação universitária se apropriar dos recursos das tecnologias para o desenvolvimento da gestão administrativa e acadêmica (YABER, 2011).

Yáber (2011) conclui que o comportamento humano em um determinado momento é resultante dos mecanismos de seleção de contingências naturais, contingências comportamentais e culturais. A análise comportamental evoluiu no estudo científico das contingências comportamentais tanto de ações diretas como de ações indiretas (análogos de contingências); no comportamento governado por regras o impacto das contingências culturais (meta e macro contingências) e o comportamento verbal, que resultaram em aplicações para a educação em todos os níveis e em particular no ensino superior.

Com a análise de sistemas comportamentais, Yáber (2011) diz que atualmente se dispõe de recursos para analisar as instituições educativas como sistemas de desempenho global e a sua complexidade e os mecanismos de seleção que operam nos mesmos para então implementar mudanças organizacionais em 
nível sistêmico; de grupos e equipes; individuais e seus processos e subprocessos acadêmicos como o currículo, instrução e certificação.

A análise comportamental aplicada, segundo Yáber (2011) é uma abordagem pioneira em aplicações para a instrução como a utilização de objetivos de aprendizagem e o ensino programado; o sistema personalizado de instrução; o ensino programado no computador; o ensinamento de precisão e desenvolvimento de fluência bem como de aplicações para a gestão do comportamento do aluno em sala de aula e durante o desenvolvimento do curso universitário.

Não existe um modelo de estrutura organizacional que todas as empresas possam seguir, não existe uma estrutura perfeita, existe aquela mais adequada as atividades e estratégias da organização (OLIVEIRA, 2012).

No passado vários aplicativos de análise comportamental foram limitados devido aos altos custos de equipamentos, programas e sistemas. Com o desenvolvimento exponencial das tecnologias da informação e da comunicação e a redução dos seus custos, que amplia consideravelmente a possibilidade de futuras aplicações de análise comportamental no ensino superior (YÁBER, 2011).

\section{CONSIDERAÇÕES FINAIS}

As mudanças ocorridas na estrutura organizacional de uma universidade pública federal brasileira devem ser observadas, estudadas e investigadas, para que sejam estabelecidos os fatores contingenciais externos e internos, causadores da mudança nas estruturas da organização, em sua forma e função. A realização de estudos sobre os contextos das universidades federais justifica-se pela possibilidade de conhecer e de construir alternativas para seu funcionamento e estrutura, em um setor com características peculiares e diferenciadas; possibilitando aprimoramento da estrutura organizacional e desempenho eficiente, eficaz e efetivo da construção e reconstrução do conhecimento, sua transmissão e disseminação. 


\title{
Organizational Structure and Operation of Brazilian Universities: literature review
}

\begin{abstract}
Organizational structure is an organization, a group of people working together to achieve common goals. An organization to define your goals gives reasons for its existence, for the top management determines the direction of the organization to define its objectives, set goals to meet them and formulate strategies to achieve their goals. The goals are the targets of management to achieve their goals. Strategies are plans specific actions that enable the organization to achieve the goals, and consequently the objectives. These are the essential elements of the organizational structure.

The coordination of organizational structures discusses the advantages and disadvantages of span of control, centralization and formalization, and relates these elements to organic and mechanistic organizational structures; identifies and evaluates the types of departmentalization, explains how the external environment, the size of the organization, technology and strategy.

This study addresses the organizational structure and participation in the management process in Brazilian universities, aimed at introducing new organizational arrangements and new management mechanisms to achieve more efficiency in public spending and efficient and effective educational systems, with control results, productivity, costs, targets, indicators and the management contract, among other topics.
\end{abstract}

Keywords: organization; innovation; performance. 


\section{Referências}

BARBALHO, C. R. S. Estrutura Organizacional de Bibliotecas Universitárias: Subsídio para sua Composição. SNBU XVII, p. 1-14, 2012. Disponível em<http://www.snbu2012.com.br/anais/pdf/4REZ.pdf>. Acesso em: 16 set. 2016.

BeltRAME, M. M. L. L.; ALPERSTEDT, G. D. Construção de política de comunicação em instituições de educação profissional, científica e tecnológica: uma proposta com base na experiência do IFSC. Navus -Revista de Gestão e Tecnologia, v. 5, n. 2, p.14-26, 2015. Disponível em <http://navus.sc.senac.br/index.php/navus/article/view/224/215>. Acesso em: 16 set. 2016.

COSTA, M. C. F.; SOUZA, B.S.S.; FELL, A.F.A. Um Estudo da Estrutura Organizacional e as Mudanças Organizacionais: Proposta de Um Novo Modelo. Navus - Revista de Gestão e Tecnologia, v. 2, p. 57-74, 2012. Disponível em $<$ http://navus.sc.senac.br/index.php/navus/article/view/62/40>. Acesso em: 16 set. 2016.

GRIFFIN,R. W; MOORHEAD, G. Projeto de estruturas organizacionais. In: . Fundamentos do comportamento organizacional. São Paulo, 2006. Cap. 12, p. 233-253.

GRIFFIN,R. W; MOORHEAD, G. Estrutura organizacional. In: . Fundamentos do comportamento organizacional. São Paulo, 2006. Cap. 13, p. 266-296.

LEITAO, S. P. Estrutura, Cultura e Desempenho Organizacional na Universidade. RAP. Revista Brasileira de Administração Pública, Rio de Janeiro, v. 24, n.nov89/jan90, p. 31-43, 1990.

KUNSCH, M. M. K. COMUNICAÇÃO ORGANIZACIONAL: Contextos, Paradigmas e Abrangência Conceitual.Matrizes (Online), v. 8, n. 2, p. 35-61, 2014. Disponível em<http://www.revistas.usp.br/matrizes/article/viewFile/90446/93218>. Acesso em: 16 set. 2016.

OLIVEIRA, V. Estrutura Organizacional. Influência da estrutura na eficiência da organização de acordo. $2012 . \quad$ Disponível em: <http://www.administradores.com.br/artigos/marketing/estrutura-organizacionalinfluencia-da-estrutura-na-eficiencia-da-organizacao-de-acordo/62071/>. Acesso em: 16. set. 2016.

VIEIRA, E. F.; VIEIRA, Marcelo Milano Falcão. Estrutura organizacional e gestão do desempenho nas universidades federais brasileiras. RAP. Revista Brasileira de Administração Pública, Rio de Janeiro, v. 4, n.37, p. 899-920, 2003.

YÁBER, G. Análisis Conductual Aplicado em la Educación Superior. Analogías del comportamiento: 12, pp. 39-71, 2011. 